\title{
Retroperitoneal venous malformation mimicking a nodal metastasis in oesophageal cancer on staging F18-FDG PET/CT
}

\author{
Amar Shah 이, ${ }^{1}$ Mohamad Sonbol, ${ }^{2}$ Longwen Chen, ${ }^{3}$ Ming Yang ${ }^{1}$
}

${ }^{1}$ Radiology, Mayo Clinic Arizona, Phoenix, Arizona, USA ${ }^{2}$ Internal Medicine, Mayo Clinic Arizona, Phoenix, Arizona, USA ${ }^{3}$ Pathology, Mayo Clinic Arizona, Phoenix, Arizona, USA

\section{Correspondence to} Dr Ming Yang;

yang.ming@mayo.edu

Accepted 25 February 2022

\section{DESCRIPTION}

A man in his 60s with longstanding Barrett's oesophagus was found to have moderately differentiated oesophageal adenocarcinoma with presumed aortocaval nodal metastasis. In addition to showing the known hypermetabolic oesophageal malignancy, F18-FDG PET/CT (F-18 fluorodeoxyglucose positron emission tomography and computed tomography) study revealed an aortocaval nodal lesion with equivalent tracer uptake to blood pool. This nodal lesion exhibited heterogeneous enhancement with a draining vein on diagnostic CT (figure 1). This lesion was initially thought to be metastatic, removing curative therapy from the treatment algorithm. However, a CT-guided biopsy demonstrated
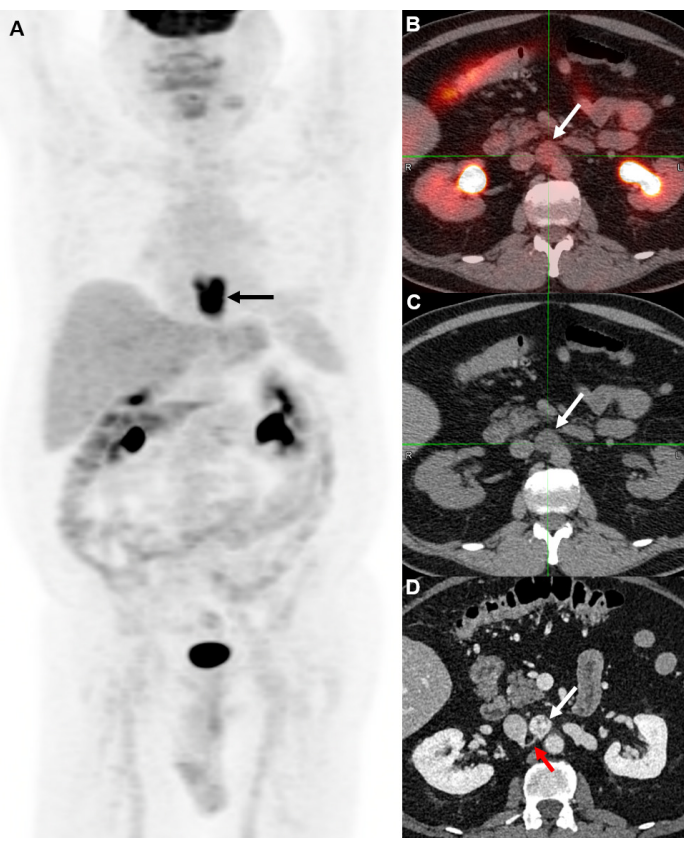

Figure 1 Staging F18-FDG PET (F-18 fluorodeoxyglucose positron emission tomography and computed tomography) maximum intensity projection (MIP) image showed known primary distal oesophagus along with intense FDG uptake, SUVmax 17.0 (black arrow in A). PET/CT fusion image (B) and low-dose CT image (C) demonstrated a $2.1 \times 1.9 \mathrm{~cm}$ low density aortocaval nodal lesion with SUVmax 2.3, equivalent to blood pool (white arrows). This node demonstrated peripheral intense enhancement and central low attenuation on diagnostic CT scan (white arrow), as well as a draining vein into inferior vena cava (red arrow), indicating a low-flow venous malformation (D).

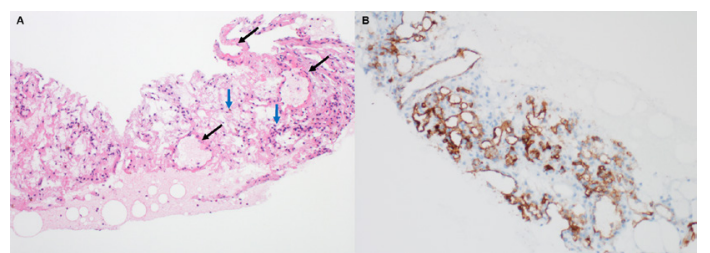

Figure 2 A CT guided biopsy was performed. (A) H\&E, $10 \times$ staining revealed a lobulated proliferation of benign vascular spaces (black arrows) with haemosiderin deposition (blue arrows). (B) CD-31 (10x) staining shows CD31-positive vascular spaces. Findings were consistent with a venous malformation.

prominent benign vascular proliferation, compatible with venous malformation. Combined with imaging findings, a definitive diagnosis of venous malformation was achieved (figure 2). With confirmed locally advanced disease (as opposed to metastatic disease), the patient was able to receive curative, rather than palliative therapy.

Venous malformation is a benign vascular proliferation and commonly occurs in skin/mucosa and visceral organs such as the liver, spleen, kidney, adrenal glands and others. While traditionally thought to represent slow-growing neoplasms (also known as cavernous haemangioma), recent studies have shown that these lesions are more accurately characterised as low-flow venous malformations. ${ }^{1}$ Retroperitoneal venous malformations (RVMs) typically arise from adjacent organs, with primary RVM arising in isolation extremely rarely. ${ }^{2}$ Most RVMs are asymptomatic unless haemorrhagic or causing extensive mass effect. Contrast-enhanced CT and MRI typically show peripheral hyperenhancement with and without gradual contrast agent filling in the venous and delayed phase. Occasionally, a draining vein may be seen, as in this case. Traditionally, nuclear medicine and PET/CT played a complementary role in the diagnosis of simple venous malformation, including typical hepatic cavernous haemangioma and the rarer RVM. ${ }^{3}$ However, imaging features are usually insufficient to distinguish benign RVM from multiple primary and secondary retroperitoneal malignancies. Given the location and rarity of the RVM, biopsy or surgical resection of retroperitoneal lesions is usually required to obtain confirmative histopathological evidence to aid diagnosis and staging purposes.

RVM is presumably non-hypermetabolic on F18FDG PET/CT scan given its benign anatomic and 
histopathologic features. ${ }^{2}$ However, delayed F18-FDG uptake was once observed in a hepatic cavernous haemangioma, which was presumably related to underlying biologic activity, vascularity and mitotic rate. ${ }^{4}$ In this patient, the lesion showed radiotracer uptake equivalent to the blood pool. In select cases, delayed blood pool images using Tc-99m UltraTag red blood cell might enhance the diagnostic accuracy as delayed blood pool activity is characteristic of low-flow venous malformations. ${ }^{3}$ This case highlights the importance of tissue sampling to establish/exclude the diagnosis of metastatic disease as the treatment intent is different.

\section{Learning points}

- Retroperitoneal venous malformation (RVM) is a rare but ultimately benign lesion in adults that can demonstrate heterogeneous contrast enhancement on CT and blood-pool level activity on PET-CT (positron emission tomography).

- While the vast majority of RVM arise via extension from adjacent organs, a small subset arises in isolation.

- Primary RVM cannot be distinguished from retroperitoneal malignancies based on imaging alone. Thus, tissue sampling is critical in equivocal cases to ensure accurate diagnosis.
Contributors MS treated the patient and reviewed the manuscript. LC performed the histopathological analysis, provided representative slices for the publication and reviewed the manuscript. AS and MY were the primary manuscript writers, consolidated the case information and prepared radiographic/nuclear medicine images for publication. All authors contributed to the drafting of the manuscript and figure legends. The final manuscript was reviewed and approved by all contributing authors.

Funding The authors have not declared a specific grant for this research from any funding agency in the public, commercial or not-for-profit sectors.

Competing interests None declared.

Patient consent for publication Consent obtained directly from patient(s)

Provenance and peer review Not commissioned; externally peer reviewed.

Case reports provide a valuable learning resource for the scientific community and can indicate areas of interest for future research. They should not be used in isolation to guide treatment choices or public health policy.

\section{ORCID iD}

Amar Shah http://orcid.org/0000-0003-3195-4491

\section{REFERENCES}

1 Merrow AC, Gupta A, Patel MN, et al. 2014 revised classification of vascular lesions from the International Society for the study of vascular anomalies: RadiologicPathologic update. Radiographics 2016;36:1494-516.

2 Higashiyama S, Kawabe J, Hayashi T, et al. A case of cavernous hemangioma in which malignancy was preoperatively excluded by FDG-PET. Ann Nucl Med 2008;22:327-30.

3 Shah M, Freeman LM, Chitkara M, et al. Retroperitoneal hemangioma demonstrated on blood pool scan. Clin Nucl Med 2014;39:e265-6.

4 Scolozzi V, Giancipoli RG, Macciomei MC, et al. Cavernous hemangioma: a potential pitfall at delayed 18F-FDG PET/CT scan. Clin Nucl Med 2021;46:e584-6.

Copyright 2022 BMJ Publishing Group. All rights reserved. For permission to reuse any of this content visit https://www.bmj.com/company/products-services/rights-and-licensing/permissions/

BMJ Case Report Fellows may re-use this article for personal use and teaching without any further permission.

Become a Fellow of BMJ Case Reports today and you can:

- Submit as many cases as you like

- Enjoy fast sympathetic peer review and rapid publication of accepted articles

- Access all the published articles

Re-use any of the published material for personal use and teaching without further permission

Customer Service

If you have any further queries about your subscription, please contact our customer services team on +44 (0) 2071111105 or via email at support@bmj.com.

Visit casereports.bmj.com for more articles like this and to become a Fellow 